\title{
AUTOMATING PHOTOGRAMMETRY FOR THE 3D DIGITISATION OF SMALL ARTEFACT COLLECTIONS
}

\author{
M.E. Marshall ${ }^{1}$, A.A. Johnson ${ }^{2}$, S.J. Summerskill ${ }^{2}$, Q. Baird ${ }^{1}$, E. Esteban ${ }^{1}$ \\ ${ }^{1}$ Factum Arte, Factum Foundation, Madrid, Spain - (matt.marshall, quinner.baird, enrique.esteban)@factumfoundation.org \\ ${ }^{2}$ Loughborough Design School, Loughborough University, UK - (A.Johnson, S.J.Summerskill2)@ lboro.ac.uk
}

Commission II, WG II/8

KEY WORDS: photogrammetry, turntable, autonomous, digitisation, 3D Scanning

\begin{abstract}
:
The 3D digitisation of precious or delicate cultural heritage artefacts via photogrammetry is highly important for historical preservation purposes. Doing so can help mitigate against events such as natural disasters, war, and tourism damage, whilst enabling access to 3D data for researchers around the globe. While the digitisation of such artefacts offer many significant societal and academic benefits, the process in which data is captured is resource intensive and often results in inaccurate outcomes. This paper presents a novel small object scanner which automates the photogrammetry image acquisition process for the highly detailed and efficient 3D digitisation of cultural heritage artefacts across large museum collections.
\end{abstract}

\section{INTRODUCTION}

The 3D digitisation of precious or delicate cultural heritage artefacts is highly important for historical preservation purposes. Doing so can help mitigate against events such as natural disasters, war, and tourism damage, whilst enabling access to 3D data for researchers around the globe.

Photogrammetry is often the preferred choice over other noncontact digitisation methods such as laser scanning or structuredlight systems for heritage conservation. This is because it enables the capture of detailed colour information of the subject and equipment is significantly cheaper. However, some disadvantages of this process includes the greater risk of errors occurring due to human error potentially leading to poor results. An operator of such a system needs a sound knowledge and practical understanding of photography and the process of photogrammetry in order to produce an optimum data set for high quality reconstruction (Historic England, 2017).

Automating the photogrammetry process would allow for a near perfect set of images for use in reconstruction software by controlling the position of the camera and object, the lighting, and camera settings. A current solution to the automation of photogrammetry is the conveyor system CultLab3D (Santo et al., 2017), and consists of two scanning units; the CultArc3D arc that is equipped with multiple cameras and lights, and the CultArm3D robotic arm.. Whilst this is sophisticated solution, the cost to purchase or leasing can be too substantial for many heritage institutions that often run on small budgets.

A more cost-effective and simple alternative solution to automate image acquisition is by using a turntable. This low cost solution (Menna et al., 2017) uses a turntable but requires the operator to manually raise the camera after each rotation. Another low cost mechanical design (Gattet et al., 2015) has featured the use of a turntable but with three cameras, which increases the overall cost significantly.

This paper presents a novel low-cost small object scanner which fully automates photo acquisition in photogrammetry for the highly detailed and efficient 3D digitisation of cultural heritage artefacts using a DSLR camera.

\section{SCANNER COMPONENTS}

\subsection{Overview of System}

The developed scanner utilises an Arduino Mega microcontroller to control three stepper motors, a servo, series of mechanical end stop safety switches, and camera trigger controls. The design, as shown in Figures 1-2, allows a camera to take images 360 degrees around the object. Specially developed software allows the user to input the object dimensions and camera specifications via a GUI to automatically generate the camera positions for image capture. These camera positions are communicated to the scanner via a processing program that guides the user through the setup and running of the machine.

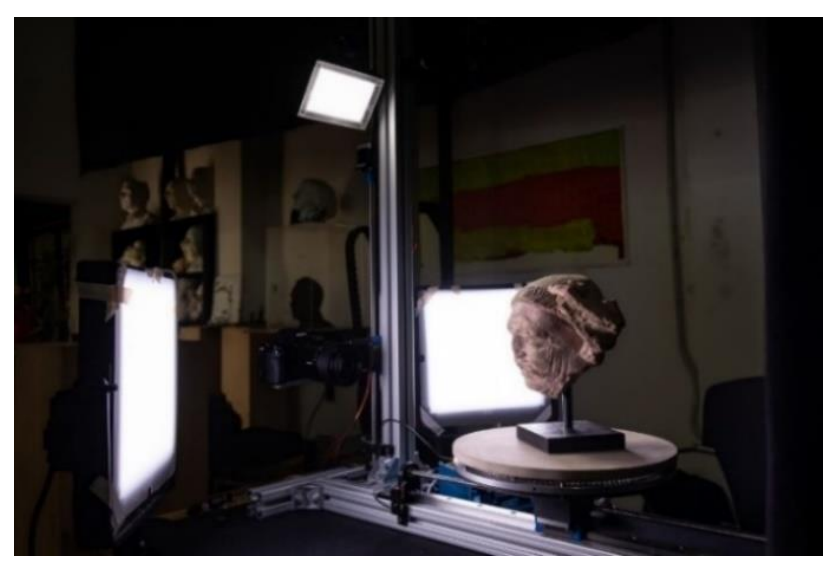

Figure 1. Small object scanner

\subsection{Hardware Components}

An Arduino Mega microcontroller was used for processing the code, due to the large amount of digital signal pins needed for components.

The developed scanning solution uses three NEMA 17 stepper motors - one to drive the turntable, and two others for each linear actuator. TB6600 stepper drivers are used to protect both the motors and electronics from overheating, and to provide current and voltage protection. The stepper motors were set to micro step to allow smooth acceleration and deceleration in order to prevent the occurrence of damage to the subject and to minimise camera shake. 


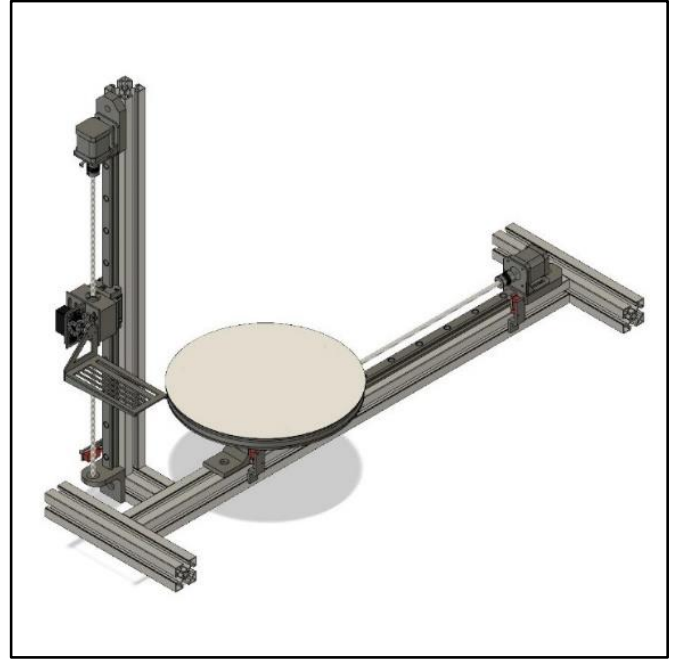

Figure 2. Mechanical design of scanner

A number of key variables informed the development of the established system, including the weight of the camera body with the lenses, the size of the camera body with lenses and the minimum focus distances of lenses. Furthermore, the maximum size of the object that could be scanned was set at $250 \mathrm{~mm} x$ $250 \mathrm{~mm} \times 250 \mathrm{~mm}$ in order to fit onto a circular turntable. With these variables identified the scanner was built to accommodate a Sony A7ii DSLR camera with $35 \mathrm{~mm}, 55 \mathrm{~mm}$, and $90 \mathrm{~mm}$ lenses. Figure 3 shows the simulation of minimum focus and depth of field for camera set-ups featuring the three identified lenses.

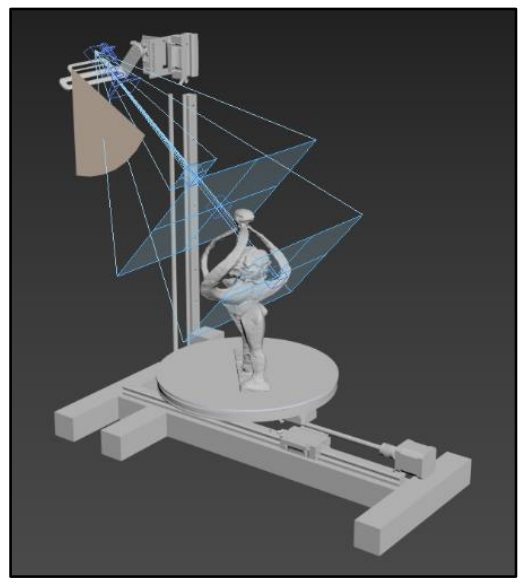

Figure 3. Virtual prototyping for lens depth of field simulation

To appropriately angle the camera, a $20 \mathrm{~kg}$ gear servo was used, with a servo driver to power the servo at a different voltage to the stepper motors. This also has an additional benefit of cleaning signal noise from the system therefore reducing the likelihood of juddering to ensure a smooth motion during data capture activities.

Mechanical end stop switches were used to improve machine safety, to prevent the machine from damaging itself, and to prevent the object being scanned from colliding with the camera set-up and core structure.

For camera control, a relay module connected to the Arduino board was used to trigger the camera. A multiport wire was used to connect the camera to the relay to control autofocus and the trigger. The use of the relay also provided a clean signal. A dual output $12 \mathrm{~V} 5 \mathrm{~V}$ DC PSU was used to enable power to the stepper motors at $12 \mathrm{~V}$ and the servo at $5 \mathrm{~V}$.

A diffused lighting setup was used to illuminate the subject consisting of three large diffused LED panels. A black photographic curtain was used as the background. Using diffused light illuminated only the subject, therefore allowing the camera to easily autofocus on the object. Additionally, this removed the need to have additional circuitry and hardware to sync flash units to the camera shutter.

\subsection{Software Components}

A script was designed in Grasshopper (Rutten, 2019) to allow an operator who is inexperienced in photogrammetry to be able to perform a scan through a dedicated graphical user interface ( NBBJ Design Computation, 2019). The user is able to input the object dimensions to create a scan envelope. The user has the option of choosing between a domed envelope, cylindrical, or spherical distribution depending on the subject being scanned. Each category has their own dimension manipulation sliders. For the program to generate the camera positions, sensor dimensions and lens focal lengths are needed. This is to perform a sensor baseline calculation factoring in field of view and minimum focus distance of the lens. The calculated camera positions, as shown in Figure 4, are then established as cartesian coordinates alongside an angle vector, all of which are recorded to a text file.

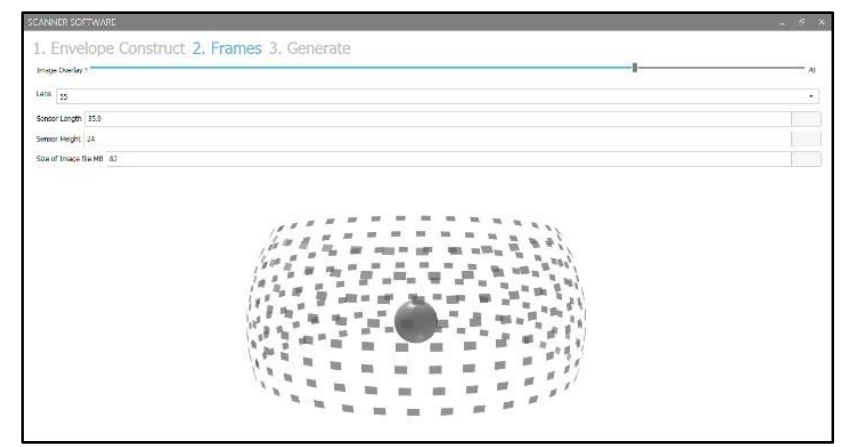

Figure 4. Generation of camera positions in software

A processing program communicates with the systems microcontroller by sending the coordinates from generated text file when the machine requests one. Giving the scanner one set of coordinates at a time relieves the need to store all of the data on the microcontroller, which for large scans would exceed the on-board memory. Additionally, a log of the progress can be kept in case there are issues mid-scan, for example in the event of a power cut or mechanical failure.

\section{VIRTUAL TESTING: RESOURCES}

Preliminary virtual tests based on calculations generated from the developed software show the average expected resources each scan will need. Further physical testing can be outlined based upon this information. The following data is based upon Sony ARii specification and a standard dome distribution of average dimension.

- $\quad$ Sensor size: 35.9 x $24.0 \mathrm{~mm}$

- Lenses: $35 \mathrm{~mm}, 55 \mathrm{~mm}$, and $90 \mathrm{~mm}$

- Raw Compressed average image size: $41 \mathrm{mb}$

- Jpeg fine average image size: $10 \mathrm{mb}$

- Average time to capture and move to next position: $3 \mathrm{~s}$ 
For example, at $80 \%$ overlap a $90 \mathrm{~mm}$ lens will need two and a half hours to scan the object and use $125 \mathrm{~GB}$ of data when saving as RAW file format. In comparison, a $55 \mathrm{~mm}$ lens at $80 \%$ image overlap will only need twenty-seven minutes and $22 \mathrm{~GB}$ of data. See Table 2 in the appendix for complete results.

The results indicated that an image overlap range of $30-80 \%$ would be suitable for physical testing. Data captured using the $90 \mathrm{~mm}$ lens was excluded due to being resource intensive.

\section{DIFFERENCE IN QUALITY BETWEEN FOCAL LENGTH AND IMAGE OVERLAP}

An assessment was made to analyse the difference in quality of images featuring a baseline overlap of between $30 \%-80 \%$. This range was based upon the preliminary virtual testing results previously discussed and outlined within Table 1.

\subsection{Testing setup and procedure}

Camera settings were used which correctly exposed the photographs. To allow for a larger depth of field, an aperture of $\mathrm{f} / 16$ was used. An online tool DxOMark (DxoMark Image Labs, 2019) was used to ensure the aperture was within the high sharpness range.

The grasshopper script was used to generate the positions needed for testing varying image overlaps, using a cylindrical distribution. The lighting seen in Figure 5, and camera settings were maintained across all tests. Images were captured in Sony RAW file format and converted to TIFF files for processing. Reality Capture (Capturing Reality s.r.o, 2019) was used for the reconstruction. The standard pipeline was used, image alignment followed by normal detail reconstruction.

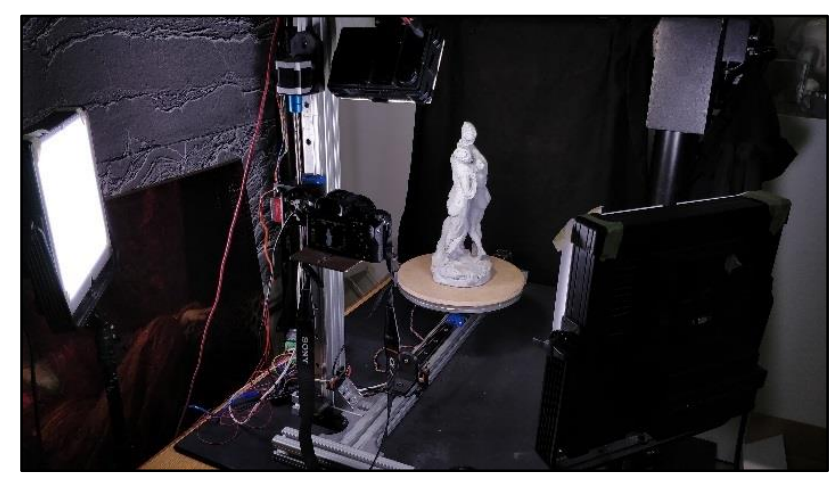

Figure 5. Test setup, three diffused lights

\subsection{Results}

Alignment of the images, seen in Figure 6 was accurate to the camera positioning array generated in the software. The network shows that there is a strong correlation between the captured images to the camera positioning data established.

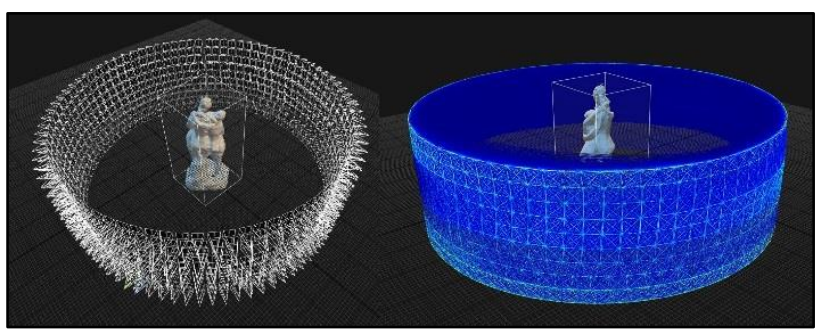

Figure 6. Left: Camera alignment Right: Network of image ties.

\begin{tabular}{|c|c|c|c|c|c|c|c|}
\hline \multirow{3}{*}{ Lens } & $\begin{array}{c}\text { Overlap } \\
\text { Percentage }\end{array}$ & $\begin{array}{c}\text { Camera } \\
\text { Count }\end{array}$ & $\begin{array}{c}\text { Points } \\
\text { Count }\end{array}$ & $\begin{array}{c}\text { Track } \\
\text { Length }\end{array}$ & $\begin{array}{c}\text { Mean } \\
\text { error }\end{array}$ & $\begin{array}{c}\text { Triangle } \\
\text { Count } \\
\text { (Millions) }\end{array}$ & $\begin{array}{c}\text { Processing } \\
\text { Time }\end{array}$ \\
\hline \multirow{5}{*}{$\mathbf{3 5 m m}$} & $30 \%$ & $\mathrm{n} / \mathrm{a}$ & - & - & - & - & - \\
\cline { 2 - 8 } & $40 \%$ & $\mathrm{n} / \mathrm{a}$ & - & - & - & - & - \\
\cline { 2 - 8 } & $50 \%$ & $\mathrm{n} / \mathrm{a}$ & - & - & - & - & - \\
\cline { 2 - 8 } & $60 \%$ & 66 & 269,385 & 2.617 & 0.31521 & 6.19 & $00: 03: 07$ \\
\cline { 2 - 8 } & $70 \%$ & 120 & 553,020 & 3.268 & 0.37950 & 7.13 & $00: 19: 36$ \\
\hline \multirow{5}{*}{$\mathbf{5 5 m m}$} & $80 \%$ & 263 & $1,017,852$ & 4.255 & 0.43949 & 7.85 & $00: 42: 52$ \\
\cline { 2 - 8 } & $30 \%$ & 36 & 61,147 & 2.383 & 0.42248 & 12.62 & $00: 07: 48$ \\
\cline { 2 - 8 } & $40 \%$ & 63 & 148,310 & 2.522 & 0.43524 & 15.81 & $00: 12: 07$ \\
\cline { 2 - 8 } & $50 \%$ & 75 & 256,253 & 2.651 & 0.45557 & 16.76 & $00: 16: 15$ \\
\cline { 2 - 8 } & $60 \%$ & 98 & 405,488 & 2.889 & 0.46577 & 17.84 & $00: 20: 19$ \\
\cline { 2 - 8 } & $70 \%$ & 210 & 957,387 & 3.507 & 0.51530 & 19.67 & $00: 43: 37$ \\
\hline
\end{tabular}

Table 1: Overlap percentage test results 


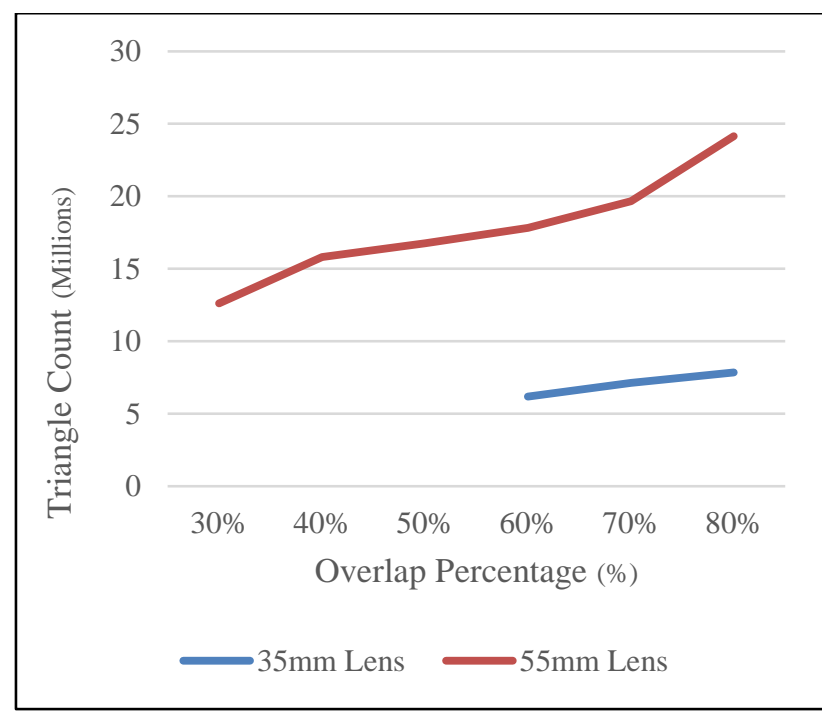

Figure 7. Triangle count per each overlap value

Images of $50 \%$ overlap and below using the $35 \mathrm{~mm}$ lens failed to align. The results as shown in Table 1 , demonstrate that the $55 \mathrm{~mm}$ lens records more detail than the $35 \mathrm{~mm}$ lens and that as the number of cameras increase, the amount of projections and points increase which in turn increases the number of polygons in the meshed model seen in Figure 7.

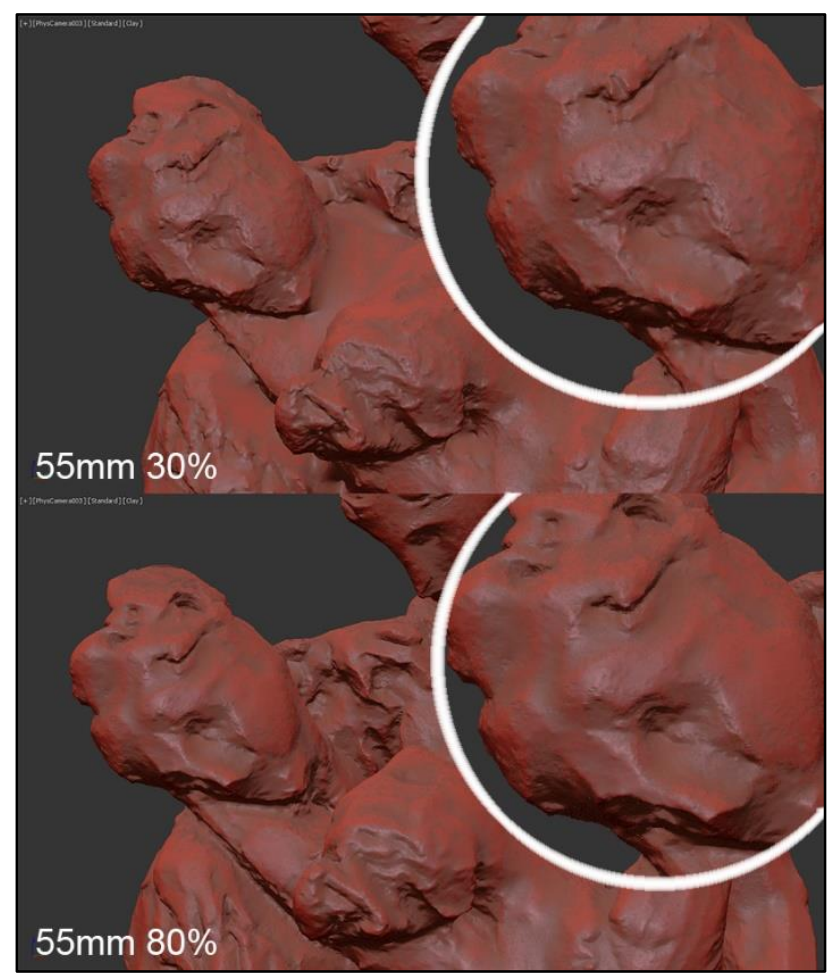

Figure 8. Quality comparison of $55 \mathrm{~mm}$ at $30 \%$ and $80 \%$ image overlap

As seen in Figure 8, the higher the overlap value the sharper and more defined features of the model became. Below $60 \%$ overlap there were areas of lower density points which reduced the resolution.

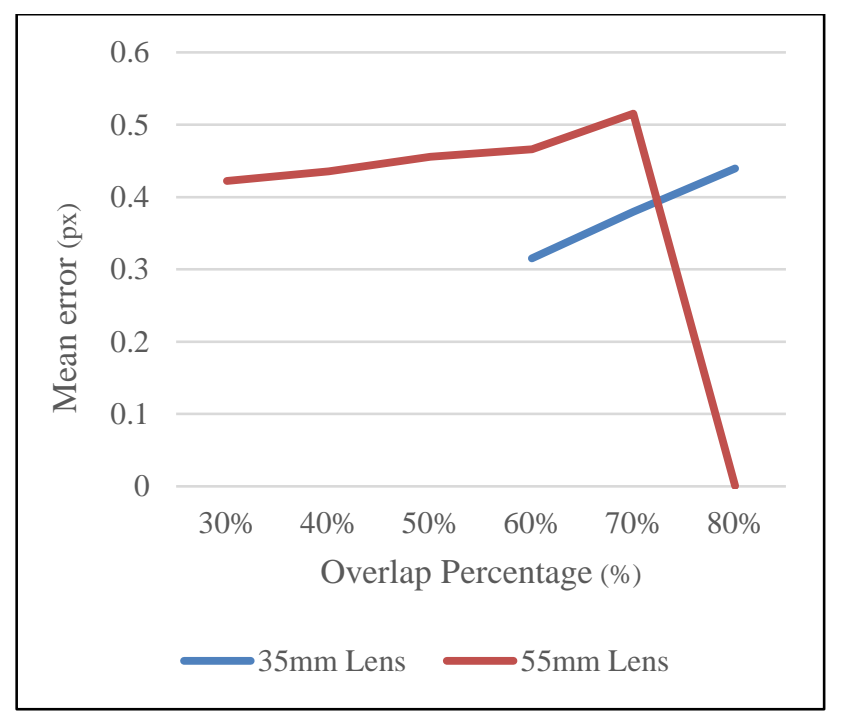

Figure 9. Projection Errors per each overlap value.

Projection errors are a statistic used to represent the difference in the position in pixels between a point in a captured image and the projection of the corresponding 3D point in the same photo. The results presented in Figure 9 show that projection errors increase as the total number of projections increase until it hits a threshold shown in $80 \%$ image overlap with the $55 \mathrm{~mm}$ lens, where the projection errors are significantly lower. This suggests that the accuracy of the points improves once reaching an image overlap above $80 \%$.

Track length is the number of images, on average, in which a point appears. In this case track length shows a significant increase at $80 \%$ with the $55 \mathrm{~mm}$ lens which could be the factor driving the minimised projection error.

\section{USE CASE - GANDHARAN CLAY HEAD}

A Gandharan clay head cultural heritage artefact dating from the $4^{\text {th }} / 5^{\text {th }}$ Century was used to assess the performance of the developed system in relation to the capture of small features and surface textures. An example of this precious artefact being scanned is shown in Figure 10.

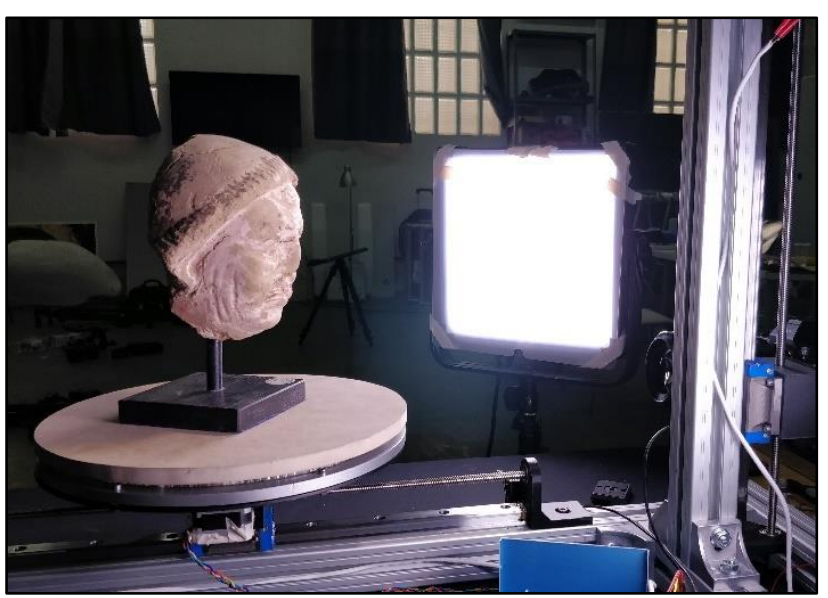

Figure 10. Artefact being scanned

The artefact was recorded using the $55 \mathrm{~mm}$ lens with $80 \%$ overlap. The resulting reconstruction was of high quality with a consistent point cloud density, capturing sub-millimetre details 
such as cracks in the clay and the flakes of paint, as shown in Figure 11 .

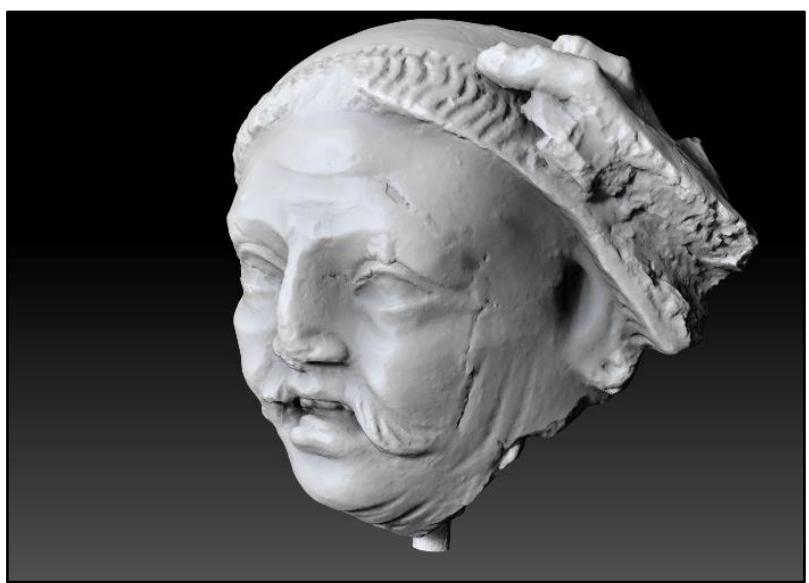

Figure 11. Data captured reconstruction of clay-fired head

The photo quality also positively impacted the texture quality resulting in a sharp high-resolution texture map.

\section{90MM LENS FEASIBILITY}

An assessment was made with regards to the feasibility of using a $90 \mathrm{~mm}$ lens for increased density and quality of mesh. This test highlighted the issues of having a small field of view and narrow depth of field.

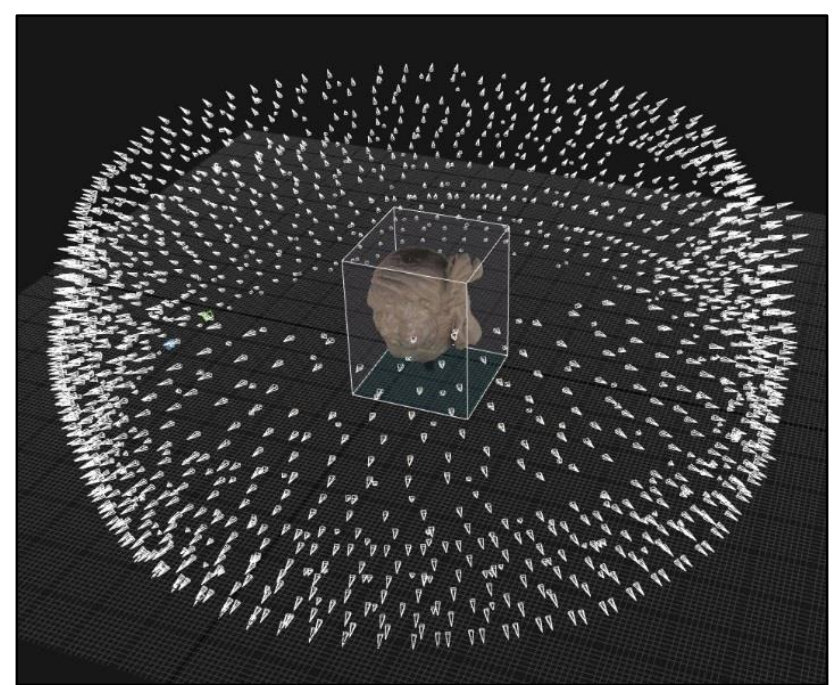

Figure 12. Camera alignment of the $90 \mathrm{~mm}$ lens

Focusing times were significantly longer as the zoom lens hunts for focus, often not finding the point of focus before the shutter is automatically released. This caused gaps in the camera alignment, seen in Figure 12 .

The depth of field caused issues as not all areas of focus were normal to the camera. This caused images to have areas of blur, reducing the overall coverage and increasing processing times. A pre-scan feature could also somewhat remedy this problem as it could generate the camera positions based upon the normal of the object surface, however, there are questions over whether this model of coverage would be efficient for photogrammetry reconstruction compared to the equally overlapped images as previously identified.

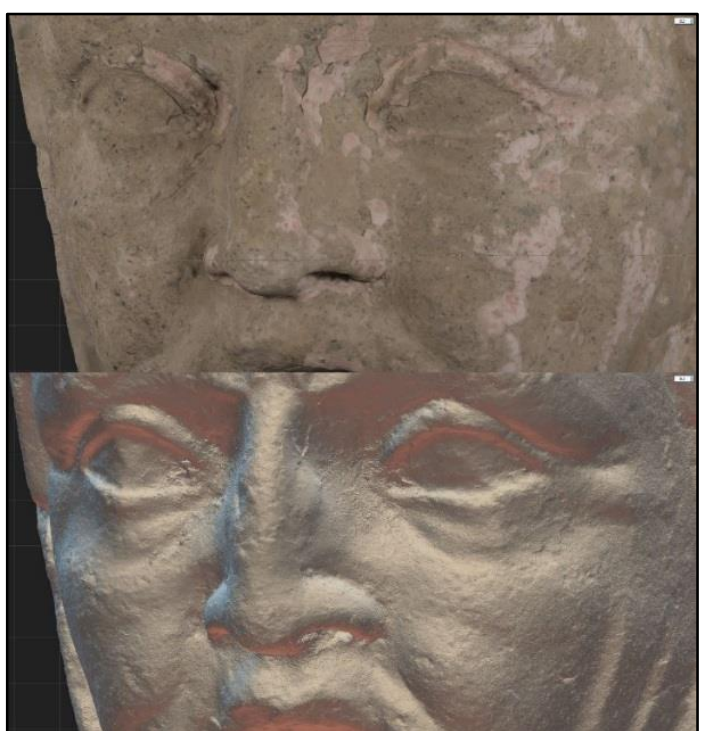

Figure 13. Textured model (top) and mesh (bottom) detail of reconstruction

The mesh detail in the $90 \mathrm{~mm}$ test seen in Figure 13, was significantly higher quality than that of the $35 \mathrm{~mm}$ and $55 \mathrm{~mm}$ tests, however it wasn't consistent over the entire scan due to the issues described above. Nevertheless, the areas that were dense captured the sub-millimetre features such as paint flakes and cracks with more detail and sharpness. The texture was not as consistently sharp as the tests with the $35 \mathrm{~mm}$ and $55 \mathrm{~mm}$ lens, which again could be due to the shallow depth of field of the $90 \mathrm{~mm}$ lens.

\section{UTILISING CAPTURED DATA}

\subsection{D Printing}

There is scope for the captured and processed data to be used for the creation of facsimiles or repairing damaged regions of an original precious artefact.

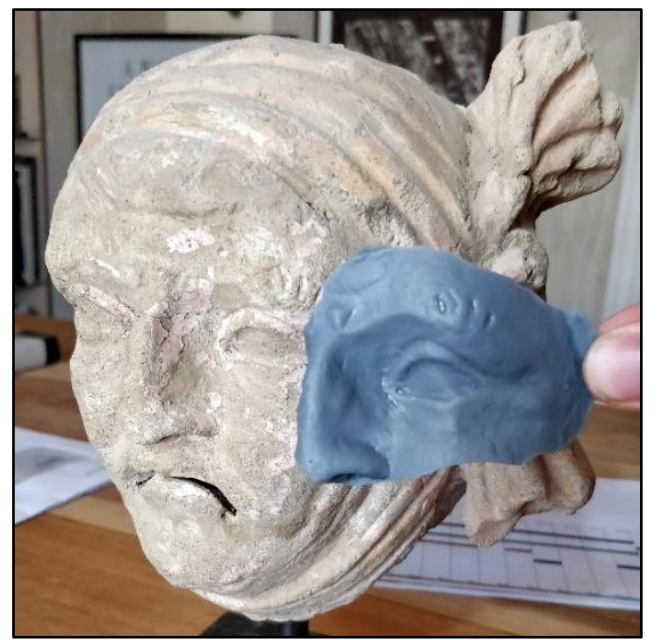

Figure $14.3 \mathrm{D}$ printed segment compared to original

Due to the vast size of the data only a small segment seen in Figure 14, could be printed at $100 \%$ quality. The desktop printing slicing software Preform (Formlabs Inc, 2019) could not handle the size of the data for anything larger however, industrial 
solutions may be able to handle larger data. At present, this severely limits the usability of the large amount of data that is generated by high quality scans.

\subsection{Visualisation}

The 3D model may be used virtually in education or research, where the model is uploaded online for anyone around the world to access. Currently only decimated scans with reduced polygon density are feasible to view in an internet browser. In this context textures play an important role in masking a low-density polygon mesh. The scanner produces sharp well exposed textures. Additional calibration tools, such as a colour checker, may be utilised to achieve true colour realism.

\section{CONCLUSIONS}

The results from this investigation have shown that it is possible to balance a range of data capture and processing variables in order to achieve scans of a desired quality. Whilst it may be good practice to record the most data as possible, to have a high-quality original from which you can scale down from, it is not always appropriate due to the level of resources available. This developed system outlined within this paper provides a feasible way of controlling the process of recording objects, to the level of resources available, which would be suitable for a range of heritage institutions and small enterprises.

\section{FUTURE WORK}

Future work may include developing the project for an opensource release. Many of the components of the scanner are offthe-shelf parts and some can be 3D printed. A customised CAD tool could be developed to generate a scanner to specific requirements based upon key variables such as the size of the subject object or the user's camera and create a bill of materials and assembly instructions.

A problem with the turntable setup outlined is that the base of an object is usually not recorded. A way to remedy this would be to flip the object and record it again, as the scans are quick. Alternatively, the rotation mechanism could be redesigned to be bespoke to a specific collection. This might then take the form of a rotating holder, rather than a turntable potentially allowing the object to be fully recorded in one scan.

To allow the system to perform very high-quality scans for oneoff specimens a pre-scan feature could be developed. This could be a quick infrared scan which could drive the array generation. This could potentially counteract the issues found using a $90 \mathrm{~mm}$ lens. The lens could be set to manual and the scan could be sped up considerably, due to it not having to hunt for focus. It could also provide camera positions for hard to reach areas of the object such as undercuts or concaved areas. Focus stacking is also an option to remove the shallow depth of field. This could be achieved by having fine micro-stepping control over the actuator which the turntable sits upon.

There are additional 3D imaging techniques which are being explored to be integrated into the system. Multispectral imaging and photometric stereo may increase the quality and accuracy of the 3D model. Additionally, multispectral imaging and cross polarisation could increase the amount of texture surface finish data such as true colour or reflectivity. This would facilitate increased realism in virtual uses or increased physical realism through the use of colour or multi-material additive manufacture.

\section{ACKNOWLEDGEMENTS}

Team at Loughborough Design School - Dr. Andrew Johnson \& Dr. Steve Summerskill.

Special thanks to Adam Lowe and the team at Factum Arte and The Factum Foundation for funding the development of the project and the expertise shared - Quinner Baird, Jorge Cano, Enrique Esteban, Otto Lowe, Adam Weigert, Abhu Dhanda.

\section{REFERENCES}

Historic England, 2017. Photogrammetric Applications for Cultural Heritage. Guidance for Good Practice. Report HEAG066, Historic England, Swindon, United Kingdom.

Capturing Reality s.r.o., 2019. Reality Capture Software, https://www.capturingreality.com (15 July 2019)

David, R., 2019. Grasshopper 3D Software, https://www.grasshopper3d.com (15 July 2019)

DxoMark Image Labs., 2019. DxoMark, https://www.dxomark.com (15 July 2019)

Formlabs Inc., 2019. Preform Software, https://formlabs.com/software (15 July 2019)

NBBJ Design Computation., 2019. HumanUI Software, https://bitbucket.org/andheum/humanui/src/master/ (15 July 2019)

Gattet, E.; Devogelaere, J.; Raffin, R.; Bergerot, L.; Daniel, M.; Jockey, P.H.; De Luca, L. (2015): A versatile and low-cost 3D acquisition and processing pipeline for collecting mass of archaeological findings on the field In: Int. Arch. Photogramm. Remote Sens. Spatial Inf. Sci., XL-5/W4, 299-305. https://doi.org/10.5194/isprsarchives-XL-5-W4-299-2015.

Menna, F., Nocerino, E., Morabito, D., Farella, E.M., Perini, M., Remondino, F., 2017. An open source low-cost automatic system for image-based 3D digitization. In: Int. Arch. Photogramm. Remote Sens. Spat. Inf. Sci. - ISPRS Arch. 42, 155-162. https://doi.org/10.5194/isprs-archives-XLII- 2-W8-155-2017

Santo, P., Ritz, M., Fuhrmann, C., Monroy, R., Schmedt, H., Tausch, R., Domajnko, M., Knuth, M., Fellner, D., 2017. Acceleration of 3D Mass Digitization Processes: Recent Advances and Challenges In: Ioannides M., MagnenatThalmann N., Papagiannakis G. (eds) Mixed Reality and Gamification for Cultural Heritage. Springer, Cham. https://doi.org/10.1007/978-3-319-49 


\section{APPENDIX}

\begin{tabular}{|c|c|c|c|c|c|}
\hline $\begin{array}{c}\text { Image } \\
\text { Overlap }\end{array}$ & Lens & $\begin{array}{c}\text { Number } \\
\text { of Images }\end{array}$ & Time to Scan & $\begin{array}{c}\text { Compressed } \\
\text { RAW (GB) }\end{array}$ & Jpeg (GB) \\
\hline \multirow{3}{*}{$\mathbf{5 0 \%}$} & $35 \mathrm{~mm}$ & 51 & $00: 02: 33$ & 2.02 & 0.51 \\
\cline { 2 - 6 } & $55 \mathrm{~mm}$ & 97 & $00: 04: 51$ & 3.98 & 0.97 \\
\cline { 2 - 6 } & $90 \mathrm{~mm}$ & 488 & $00: 24: 24$ & 20.01 & 4.88 \\
\hline \multirow{3}{*}{$\mathbf{6 0 \%}$} & $35 \mathrm{~mm}$ & 84 & $00: 04: 12$ & 3.44 & 0.84 \\
\cline { 2 - 6 } & $55 \mathrm{~mm}$ & 152 & $00: 07: 36$ & 6.23 & 1.52 \\
\cline { 2 - 6 } & $90 \mathrm{~mm}$ & 777 & $00: 38: 51$ & 31.86 & 7.77 \\
\hline \multirow{3}{*}{$\mathbf{7 0 \%}$} & $35 \mathrm{~mm}$ & 166 & $00: 08: 18$ & 6.81 & 1.66 \\
\cline { 2 - 6 } & $55 \mathrm{~mm}$ & 281 & $00: 14: 03$ & 11.52 & 2.81 \\
\cline { 2 - 6 } $\mathbf{8 0 \%}$ & $90 \mathrm{~mm}$ & 1382 & $01: 06: 24$ & 54.45 & 13.28 \\
\cline { 2 - 6 } & $35 \mathrm{~mm}$ & 392 & $00: 16: 27$ & 13.49 & 3.29 \\
\cline { 2 - 6 } & $55 \mathrm{~mm}$ & 543 & $00: 27: 09$ & 22.26 & 3.43 \\
\hline \multirow{3}{*}{$\mathbf{9 0 \%}$} & $35 \mathrm{~mm}$ & 3068 & $02: 33: 24$ & 125.79 & 13.87 \\
\cline { 2 - 6 } & $55 \mathrm{~mm}$ & 1387 & $01: 09: 21$ & 56.87 & 22.78 \\
\cline { 2 - 6 } & $90 \mathrm{~mm}$ & 12289 & $10: 14: 27$ & 503.85 & 122.89 \\
\hline
\end{tabular}

Table 2. Results of preliminary virtual testing 